\section{Depression treatment in individuals with cancer: a comparative analysis with cardio-metabolic conditions}

Pallavi B. Rane, Usha Sambamoorthi, Suresh Madhavan

Department of Pharmaceutical Systems \& Policy, School of Pharmacy, West Virginia University, Morgantown, WV, USA

\section{Abstract}

A clear picture of the current state of nationwide depression treatment practices in individuals with cancer and depression does not exist in the United States (US). Therefore, the primary objective of this study was to examine rates of any depression treatment among individuals with cancer and depression in the US. To better understand the relationship between any treatment for depression and presence of cancer, we used a comparison group of individuals with cardio-metabolic conditions owing to the similar challenges faced in management of depression in individuals with these conditions. We used a retrospective cross-sectional design and data from multiple years of the Medical Expenditure Panel Survey, a nationally representative household-survey on healthcare utilization and expenditures. Study sample consisted of adults aged 21 or older with selfreported depression and cancer $(n=528)$ or self-reported depression and diabetes, heart disease or hypertension ( $\mathrm{n}=1643)$. Depression treatment comprised of any use of antidepressants and/or any use of mental health counseling services. Treatment rates for depression were $78.0 \%$ and $81.7 \%$ among individuals with cancer and cardio-metabolic conditions respectively. After controlling for socio-demographic, access-to-care, number of physician-visits, health-status, and lifestyle risk-factors related variables; individuals with cancer were less likely to report any treatment for depression (Adjusted Odds Ratio $=0.67 ; 95 \%$ Confidence Interval $=0.49,0.92)$ compared to individuals with cardio-metabolic conditions $(\mathrm{P} \leq 0.01)$. Our findings highlight the possibility that competing demands may crowd out treatment for depression and that cancer diagnosis may be a barrier to depression treatment.

\section{Introduction}

Higher rates of co-occurring depression in individuals with chronic physical illnesses compared to their age matched healthy con- trols have been well documented. Studies have also documented the negative consequences of depression on health outcomes among such individuals with physical illness and co-occurring depression. ${ }^{1-3}$ Co-occurrence of depression and physical illnesses has shown to present challenges in management of depression. ${ }^{4-6}$ Symptoms of depression may often be mistaken for symptoms related to the physical illnesses. ${ }^{7-9}$ Demands from management of physical illness can compete for clinical attention, ${ }^{5}$ which may crowd out the treatment of depression. Clinical trials of individuals with depression and a single chronic condition provide convincing evidence that depression treatment with antidepressants and/or psychotherapy reduces depressive symptoms. However, the extent to which such treatments influence chronic disease outcomes is unclear.10,11 For example, the multicenter trial Enhancing Recovery in Coronary Heart Disease found that depression treatment did not improve reinfarction-free survival after acute myocardial infarction. ${ }^{10}$ Similarly among individuals with diabetes, glyecmic control was minimally improved by depression treatment.11

As is the case with other physical illnesses, depression care among individuals with cancer can be challenging. Management of depression in cancer which is now considered as a chronic illness is currently a major area of emphasis. ${ }^{12,13}$ And with the growing number of cancer survivors, attention is now directed towards improving psychological well-being including treatment for depressive disorders in this population. As in other chronic physical illnesses, the reported prevalence of depression in cancer is high and ranges between 3 to $38 \%$ for major depression and between 1.5 to $52 \%$ for depression spectrum syndromes. ${ }^{14}$ The prevalence rates of depression varies among individuals with cancer, by cancer type and are high for those with pancreatic cancer (ranging 38-50\%), breast cancer (ranging 14-40\%) and lung cancer (ranging between 4.7-33\%). ${ }^{14}$

Depression among individuals with cancer has been associated with a negative impact on patient's quality of life, reduced acceptance of and compliance with treatment plans, prolonged hospitalizations, poor survival, reduced effective coping, or even a desire for early death or suicide.7,15,16 Recognizing the adverse effects of depression among individuals with cancer, clinical practice guidelines recommend that a combination of psychotherapy and pharmacotherapy should be used for treating depression in individuals with cancer and depression.17-19 However, it is not known whether these guidelines are widely adopted, due to the paucity of studies on treatment rates for depression among individuals with cancer. In a handful of studies on antidepressant use for depression among individuals with cancer, depression treatment rates varied from $11 \%$ to
Correspondence: Pallavi B. Rane, 960 Chestnut Ridge Rd, Apt 316, Morgantown, WV 26505, USA. Tel. +1.412.580.4938.

E-mail: pallavibrane@gmail.com

Key words: antidepressants, cancer, cardio-metabolic, depression, mental health counseling.

Funding: the authors received support from Agency for Healthcare Research and Quality Grant No. R24HS018622-01.

Contributions: PR and US designed the study, analyzed and interpreted the data, and wrote the paper; SM contributed to the conception and design of the study and also critically revised the content of the manuscript.

Conflict of interests: the authors declare no potential conflict of interests.

Received for publication: 16 October 2012.

Revision received: 18 November 2012.

Accepted for publication: 20 November 2012.

This work is licensed under a Creative Commons Attribution NonCommercial 3.0 License (CC BYNC 3.0).

(C) Copyright P.B. Rane et al., 2013

Licensee PAGEPress, Italy

Health Psychology Research 2013; 1:e2 doi:10.4081/hpr.2013.e2

$77 \% .7,20,21$ Using data from community oncology practices in the United States (US), one study reported that antidepressant treatment for depression was initiated only in a minority of individuals (16\%), and among those with colon cancer it was even lower with only $11 \%$ being prescribed antidepressants. ${ }^{7}$ Among individuals with cancer seeking healthcare in a primary care settings ( $\mathrm{n}=1513)$, only one-third of individuals with cancer received a full dose of medication. ${ }^{20}$ In this study, use of antidepressants varied from $64 \%$ in individuals with cancer and other comorbidities to $77 \%$ among individuals with cancer and without comorbidities. ${ }^{20}$ And although women are twice as likely as men to have depression, 22 in another study conducted among low-income ethnic minority women with breast/gynecologic cancers and major depression receiving care at an urban public medical center; it was found that only $12 \%$ reported receiving antidepressant medication and 5\% reported seeking psychotherapy. ${ }^{21}$ These variations in depression treatment rates can be partially explained by differential settings, provider types, and types of cancer. While most of these studies documented low rates of depression treatment among individuals with cancer, they do not provide a clear picture of the current state of nation-wide depression treatment practices in the US. 
Therefore, the primary objective of the study is to examine rates of any depression treatment that includes use of antidepressants and/or psychotherapy, among individuals with cancer and depression in the US. To better understand the relationship between any treatment for depression and presence of cancer, we used a comparison group of individuals with cardio-metabolic conditions. This comparison group was chosen due to the similar challenges faced in management of depression between individuals with cancer and cardiometabolic conditions. Both groups have high prevalence of diagnosed depression, $9,14,23,24$ for example, the prevalence of depression in individuals with diabetes mellitus ranges from 9 to $26 \%$ and from 7 to $63 \%$ in those with heart failure. 24,25 Individuals from the both groups suffer similar negative impact of depression on health outcomes.4,7,9,15,16,24,26 In addition, there has been a lack of robust evidence from clinical trials on the effectiveness of depression treatment on physical illness outcomes in both cancer and cardio-metabolic conditions. $4,8,27$ Furthermore, in both groups, competing demands in clinical care encounters may be a barrier to depression treatment. ${ }^{5}$

Treating depression in individuals with cancer can be even more challenging when compared to treating depression in individuals with other physical illnesses such as diabetes, heart disease, and hypertension. Cancer is often considered as a clinically dominant condition that consumes all the attention of healthcare providers, as the limited patient-physician interaction in clinical settings is usually spent focusing on the treatment of cancer.8,28,29 Depression may often be considered as a sequelae of cancer or cancer diagnosis and treatment. ${ }^{30}$ Very few (17\%) individuals with cancer discuss their mental health concerns after a cancer diagnosis and this may also affect depression care. ${ }^{31}$ It is a possibility that depression treatment may be less likely among individuals with cancer compared to those with cardio-metabolic conditions. On the other hand, management of depression among individuals with cancer has been recognized as a critical component of cancer care in recent years. ${ }^{17-19}$ Additionally, physicians may also consider use of antidepressants among individuals with cancer and depression, due to their other beneficial effects in terms of relieving common symptoms associated with cancer such as chronic and neuropathic pain. ${ }^{8}$ Therefore, it is also possible that individuals with cancer are as likely to receive depression treatment as compared to those with cardio-metabolic conditions. Thus, the association between any depression treatment and presence of cancer diagnosis remains poorly understood. The current study uses a nationally representative data on individuals with cancer and depression to further elucidate this relationship.

\section{Materials and Methods}

\section{Study design}

We used a cross-sectional study design and data from multiple years of the Medical Expenditure Panel Survey (MEPS) for the current study. MEPS is a nationally representative survey of the US non-institutionalized civilian population sponsored by the Agency for Healthcare Research and Quality. The MEPS collects detailed information for each person in the household from the sampling frame on demographic, socio-economic, chronic conditions, healthcare utilization, expenditures and health status information. Information is reported by a single household respondent and collected by MEPS via computer assisted personal interviews in a series of five interviews covering two full calendar years. Each year a new MEPS annual sample referred as panel is selected and followed for a period of two years. $^{32}$ For purposes of this study, we only used cross-sectional calendar year data.

\section{Data}

In this study, we pooled MEPS files for multiple years 2006, 2007 and 2008. We derived data by merging files on household characteristics, medical conditions, prescribed medicines, outpatient visits, and office-based medical provider visits. There were a total of 93,209 individuals (32,577 from year 2006; 29,370 from year 2007; and 31,262 from year 2008) included in MEPS for the three years.

\section{Study sample}

Our analytical sample was based on living adults over 21 years of age and who were alive during the calendar years and reported having depression. We defined depression in the current study as presence of major depressive disorder (single and recurrent episodes), dysthymic disorder, and mood disorder. Among these adults with depression, we limited our sample to those who reported cancer or one of the cardio-metabolic conditions (i.e. diabetes or heart disease or hypertension). Thus our final sample consisted of 2171 adults with depression and cancer $(\mathrm{n}=528)$ and adults with depression and cardio-metabolic conditions ( $\mathrm{n}=1643)$.

\section{Identification of individuals with depression, cancer and \\ cardio-metabolic conditions}

We identified individuals with depression, cancer and cardio-metabolic conditions from the MEPS medical conditions file using a combination of ICD-9-CM codes and the clinical classification codes (See Appendix). In MEPS, the medical condition file contains an observation for every self-reported medical condition the individual experienced during the year. Information on acute and chronic medical conditions is collected from the household respondents by querying whether: i) the person has been diagnosed with specific conditions, ii) the person had any conditions which were linked with medical events such as emergency visits and others, iii) the person had conditions which caused them any disability, and iv) the person had chronic conditions which bothered them during a specific reference period (in terms of the time of the interview). Information on self-reported medical conditions is collected verbatim and first converted into International Classification of Diseases, Clinical Modification, 9th edition (ICD-9 codes), which are then converted into clinical classification codes by professional coders. The codes are routinely verified and error rates have not found to exceed $2.5 \%$ for any coders in the past. ${ }^{32}$

Individuals with depression were classified in two groups: i) those with cancer and ii) those with any cardio-metabolic condition and without cancer. The rationale for this grouping is based on the framework provided by Piette and Kerr. ${ }^{29}$ In their conceptual framework, Piette and Kerr listed cancer as a clinically dominant condition that eclipses the management of other health problems. Therefore, we categorized individuals with cancer regardless of presence of any other chronic conditions including cardio-metabolic conditions, into one group (i.e. those with cancer). Cardiometabolic conditions consisting of chronic physical illnesses such as diabetes-mellitus, heart problems or hypertension were grouped together because they can be considered as concordant chronic conditions which share a similar risk profile and synergistic treatment goals. These conditions have similarly been clustered together in previous studies. ${ }^{33}$

\section{Measures}

\section{Dependent variable, any treatment for depression}

The two therapeutic modalities for depression treatment are: antidepressants and psychotherapy. ${ }^{34}$ Therefore, we included both antidepressant use and psychotherapy as our measure of depression treatment.

Antidepressants: in the MEPS prescribed medicine files, therapeutic classes and subclasses are assigned to different prescribed medicines through linkage with the Multum Lexicon database. ${ }^{32,35}$ We identified antidepressants using the therapeutic subclass class code (249). Depression treatment with antidepressants was defined in our study, as any reported prescription drug event for antidepressants during each calendar year.

Psychotherapy: data on psychotherapy/counseling visits was derived from the MEPS outpa- 
tient visits file and the office-based medical provider visits file for calendar years 2006, 2007 and 2008; which provided information on the types of treatments, procedures, and services during each self-reported visit in this period. Individuals with at least one visit on record for psychotherapy/counseling were considered as receiving psychotherapy for depression in our study. Psychotherapy has similarly been identified in the past, in studies that used the MEPS data. 6,36

We then combined the use of antidepressants and/or psychotherapy to classify depression treatment into two categories: i) received no depression treatment and ii) received any depression treatment (as we did not have a large sample size for psychotherapy alone, see Appendix).

\section{Independent variables}

We included demographic characteristics such as gender (female, male), race/ethnicity (White, African American, Latino, Other); age (categorized as 22-39 years, 40-49 years, 50-64 years, 64 years and above); marital status (married, widowed, separated/divorced, never married) and metropolitan status (categorized as metropolitan/non-metropolitan) as independent variables in our analysis. The US Census bureau defines geographical regions as having a metro or metropolitan status when they have a relatively high population density at its core and has a high degree of social and economic ties throughout the area. We also looked at socioeconomic characteristics such as their level of education (categorized as less than high school, high school, more than high school); employment status (employed, not employed) and family poverty status (categorized as poor, near poor, middle income, high income). We assessed access to health care by the type of insurance coverage (private, public, uninsured). Additionally, we looked at the number of visits to either office-based provider or outpatient hospital clinics (categorized into quintiles) as a proxy for contact with the health care system. We assessed perceived physical health and mental health status of these individuals (both categorized as excellent/very good, good, fair/poor). We also included variables related to the individual's lifestyle risk factors such as current smoking status (current smoker, other); physical exercise (3 times a week, no exercise) and body mass index (under-weight/normal, over-weight, obese). As $5.8 \%$ of individuals had missing data on current smoking, we included a missing indicator for this variable. Results for the missing indicator are not presented in the tables.

\section{Statistical techniques}

We conducted chi-square analyses to examine the unadjusted association between depression treatment and presence of cancer compared to cardio-metabolic conditions. We tested the differences in any depression treatment received between cancer and cardiometabolic groups for each level of the independent variables. For example, among all women, the relationship between any depression treatment and cancer was examined with cardio-metabolic condition group as the reference group. Similarly among all men, the relationship between any depression treatment and cancer was examined using cardio-metabolic condition group as the reference group. Results were summarized in terms of odds ratios (OR) and 95\% confidence intervals (CI). Such approaches have been used in testing subgroup differences. 37 We then adjusted for the independent variables listed above within a framework of multivariable logistic regression to analyze the independent relationship between depression treatment and cancer. Here, the dependent variable consisted of: i) any depression treatment received and ii) no depression treatment received which was used as a reference category. The independent variables such as gender, race/ethnicity, marital status, metro status, level of education, family poverty status, employment status, type of health insurance, perceived physical and mental health status, current smoking, physical exercise, body mass index and number of visits to office-based provider or outpatient hospital clinics were entered in blocks in the regression model and several models were tested. The cardio-metabolic group served as a reference group in all these models. We transformed the parameter estimates derived from the logistic regression to adjusted odds ratios (AORs), and their corresponding 95\% CI. We used the appropriate weights and strata provided in the MEPS data, to control for the clustering and the unequal probability design. All the analyses were conducted using the survey procedures in SAS 9.2.

\section{Results}

The description of our study sample of 2,171 individuals, aged 21 years and older, with depression and cancer or cardio-metabolic conditions is summarized in Table 1 (for additional description of the study sample, please see Appendix). Our study sample comprised of 528 adults with depression and cancer, and 1643 adults with depression and cardio-metabolic conditions. Based on chi-square tests, statistically significant differences in some characteristics were observed among individuals with cancer and cardio-metabolic conditions. Higher percentages $(86.6 \%$ versus $78.3 \%$ ) of individuals of white race/ethnicity were found in the cancer group as compared to the cardio-metabolic group. In terms of age, a higher percentage of elderly aged 65 years and above were found in the cancer group (46.6\% versus $30 \%$ ) as compared to the cardio-metabolic group. And a higher percentage of individuals with cancer belonged to the high income group (41.5\% versus $31.4 \%$ ) as compared to those from the cardio-metabolic group. Fewer individuals (4.4\%) from the cancer group were uninsured as compared to those from the cardio-metabolic group (7.4\%). Also, there were more individuals in the cancer group in comparison to the cardio-metabolic group who had a higher number of visits to office-based provider or outpatient hospital clinics $(28.7 \%$ versus $18.2 \%$ in the fifth quintile, and $22 \%$ versus $20.8 \%$ in the fourth quintile respectively). More individuals with cancer reported their general health $(26.5 \%)$ to be excellent/very good in comparison to those with cardio-metabolic conditions (17.2\%). There were fewer individuals in the cancer group compared to the cardio-metabolic group, who currently smoked ( $17.2 \%$ versus $23.6 \%)$, who were obese ( $33.8 \%$ versus $54.1 \%)$, and who did not exercise (62.7 versus $67.5 \%$ ). Thus, not only did the individuals from the cancer group exhibit a higher socio-economic status and better health profile, but they also reported to be practicing healthier lifestyle, as compared to the individuals from the cardiometabolic group. No statistically significant differences were observed between the two condition groups for characteristics such as marital status, metropolitan status, level of education, and employment status.

Group differences in any depression treatment across the two groups are summarized in Table 2. We present weighted percentages with depression treatment across the two groups. Overall, individuals with cancer were less likely to receive depression treatment, with $78 \%$ receiving treatment for depression as compared to $81.7 \%$ of those with depression and cardiometabolic conditions. This overall difference was not found to be statistically significant. However, statistically significant differences in depression treatment were observed in some subgroups: African Americans, younger adults in the age group 22-39 years and those who were in the higher quintile groups of number of visits to the physician. In all these subgroups, fewer individuals from the cancer group received any depression treatment as compared to their counter-parts from the cardio-metabolic group (Table 2). We also looked at unadjusted OR from logistic regressions on depression treatment in which cardio-metabolic condition group served as the reference category for each level of the subgroups. Results similar to our chi-square analysis were noticed. For example, fewer younger individuals aged 22-39 years (54.2\%) in the cancer group received depression treatment as compared to their counterparts in the cardio-metabolic group (75.8\%) and 
the unadjusted $\mathrm{OR}$ was 0.38 with $95 \% \mathrm{CI}=(0.15$, 0.95). In terms of number of visits to the physician which were categorized in quintiles, fewer individuals from the cancer group received depression treatment as compared to their counter-parts from the other group across all the five quintiles for example, $90.5 \%$ versus $83.5 \%$ [with $\mathrm{OR}=0.56,95 \% \mathrm{CI}=(0.30,1.05)$ ] in the fourth quintile and $52.2 \%$ versus $70 \%$
$[\mathrm{OR}=0.47,95 \% \mathrm{CI}=(0.25,0.88)$ in the first quintile.

AORs and 95\% CIs from the multivariable logistic regressions are presented in Table 3 . As mentioned previously, the referent category for the dependent variable was no depression treatment. Although in our bivariate analysis, individuals with cancer were found to be less likely to receive depression treatment as compared to those with depression and cardio-metabolic conditions, this relationship was not found to be statistically significant. This relationship continued to stay non-significant in our initial regression model which controlled for demographic, socioeconomic, access to care, health status, and lifestyle risk factors related variables; individuals with cancer were less likely to report treatment for depression $[\mathrm{AOR}=0.75 ; 95 \% \mathrm{CI}=(0.55$,

Table 1. Description of study sample characteristics among individuals with Depression and Cancer or Cardio-metabolic conditions. Medical Expenditure Panel Survey, 2006-2008.

\begin{tabular}{|c|c|c|c|c|c|}
\hline & & & $\mathrm{Ca}$ & bolic & Sig \\
\hline & $\mathbf{N}$ & $\mathbf{W t} \%$ & $\mathbf{N}$ & Wt $\%$ & \\
\hline All & 528 & 100 & 1643 & 100 & \\
\hline $\begin{array}{l}\text { Gender } \\
\text { Women } \\
\text { Men }\end{array}$ & $\begin{array}{l}346 \\
182\end{array}$ & $\begin{array}{l}64.9 \\
35.1\end{array}$ & $\begin{array}{l}1143 \\
500\end{array}$ & $\begin{array}{l}67.7 \\
32.3\end{array}$ & \\
\hline $\begin{array}{l}\text { Race/ethnicity } \\
\text { White } \\
\text { African American } \\
\text { Latino } \\
\text { Other }\end{array}$ & $\begin{array}{l}414 \\
40 \\
46 \\
28\end{array}$ & $\begin{array}{l}86.6 \\
3.7 \\
4.3 \\
5.4\end{array}$ & $\begin{array}{c}1056 \\
223 \\
288 \\
76\end{array}$ & $\begin{array}{l}78.3 \\
8.4 \\
8.9 \\
4.4\end{array}$ & *** \\
\hline $\begin{array}{l}\text { Age in years } \\
22-39 \\
40-49 \\
50-64 \\
65 \text { years and above } \\
\end{array}$ & $\begin{array}{c}48 \\
75 \\
175 \\
230\end{array}$ & $\begin{array}{c}9.3 \\
12 \\
32.1 \\
46.6\end{array}$ & $\begin{array}{l}168 \\
289 \\
732 \\
454\end{array}$ & $\begin{array}{l}10.3 \\
16.1 \\
43.5 \\
30.1 \\
\end{array}$ & ${ }^{* * *}$ \\
\hline $\begin{array}{l}\text { Poverty status } \\
\text { Poor } \\
\text { Near poor } \\
\text { Middle income } \\
\text { High income }\end{array}$ & $\begin{array}{c}83 \\
127 \\
138 \\
180\end{array}$ & $\begin{array}{c}10 \\
22.5 \\
26 \\
41.5\end{array}$ & $\begin{array}{l}396 \\
424 \\
420 \\
403\end{array}$ & $\begin{array}{l}16.3 \\
23.4 \\
28.9 \\
31.4\end{array}$ & $* * *$ \\
\hline $\begin{array}{l}\text { Health insurance } \\
\text { Private } \\
\text { Public } \\
\text { Uninsured } \\
\end{array}$ & $\begin{array}{l}311 \\
189 \\
28 \\
\end{array}$ & $\begin{array}{c}67.4 \\
28.2 \\
4.4 \\
\end{array}$ & $\begin{array}{l}812 \\
673 \\
158 \\
\end{array}$ & $\begin{array}{c}58.8 \\
33.8 \\
7.4 \\
\end{array}$ & ${ }^{* *}$ \\
\hline $\begin{array}{l}\text { Perceived general health } \\
\text { Excellent/very good } \\
\text { Good } \\
\text { Fair/poor }\end{array}$ & $\begin{array}{l}127 \\
132 \\
269\end{array}$ & $\begin{array}{l}26.5 \\
24.4 \\
49.1\end{array}$ & $\begin{array}{l}237 \\
513 \\
893\end{array}$ & $\begin{array}{l}17.2 \\
33.1 \\
49.7\end{array}$ & *** \\
\hline $\begin{array}{l}\text { Perceived mental health } \\
\text { Excellent/very good } \\
\text { Good } \\
\text { Fair/poor }\end{array}$ & $\begin{array}{l}163 \\
186 \\
179\end{array}$ & $\begin{array}{l}32.5 \\
35.2 \\
32.2\end{array}$ & $\begin{array}{l}425 \\
601 \\
617\end{array}$ & $\begin{array}{l}29.2 \\
37.5 \\
33.2\end{array}$ & \\
\hline $\begin{array}{l}\text { Current smoking } \\
\text { Current smoker } \\
\text { Other }\end{array}$ & $\begin{array}{l}103 \\
391\end{array}$ & $\begin{array}{l}17.2 \\
76.5\end{array}$ & $\begin{array}{c}402 \\
1149\end{array}$ & $\begin{array}{l}23.6 \\
71.1\end{array}$ & $*$ \\
\hline $\begin{array}{c}\text { Physical activity } \\
3 \text { times/week } \\
\text { No exercise }\end{array}$ & $\begin{array}{l}195 \\
329\end{array}$ & $\begin{array}{c}36 \\
62.7\end{array}$ & $\begin{array}{c}528 \\
1114\end{array}$ & $\begin{array}{l}32.5 \\
67.5\end{array}$ & ${ }^{* * *}$ \\
\hline $\begin{array}{l}\text { Body mass index } \\
\text { Underweight/normal } \\
\text { Overweight } \\
\text { Obese }\end{array}$ & $\begin{array}{l}166 \\
158 \\
189\end{array}$ & $\begin{array}{c}32 \\
30.4 \\
33.8\end{array}$ & $\begin{array}{l}291 \\
426 \\
893\end{array}$ & $\begin{array}{l}18.4 \\
25.7 \\
54.1\end{array}$ & $* * *$ \\
\hline $\begin{array}{l}\text { Number of visits to the physician } \\
\text { Quintile } 5 \\
\text { Quintile } 4 \\
\text { Quintile } 3 \\
\text { Quintile } 2 \\
\text { Quintile } 1\end{array}$ & $\begin{array}{l}152 \\
117 \\
95 \\
94 \\
70\end{array}$ & $\begin{array}{l}28.7 \\
22.1 \\
17.9 \\
17.8 \\
13.2\end{array}$ & $\begin{array}{l}299 \\
343 \\
295 \\
354 \\
352\end{array}$ & $\begin{array}{c}18.2 \\
20.8 \\
18 \\
21.5 \\
21.4\end{array}$ & *** \\
\hline
\end{tabular}

Based on 2171 living adults over age 21 who were alive during the calendar years, with self-reported depression and cancer or cardio-metabolic condition from MEPS data in years 2006,2007 and 2008. Asterisks represent significant differences between cancer and cardio-metabolic group based on chi-square tests. Number and percent of those with missing data for current smoking status, physical activity, and body mass index are not reported. Sig, Significance. ${ }^{* * *} \mathrm{P}<0.001 ;{ }^{* *} 0.001<\mathrm{P}<0.01 ;{ }^{*} 0.01<\mathrm{P}<0.05$ 
1.04)]. However this relationship became statistically significant with the AOR of 0.67 with $95 \%$ $\mathrm{CI}=(0.49,0.92)$ in our final regression model (Table 3) which also controlled for the total number of visits to the physician in addition to all other variables described above in our other model. In our final model, women were more likely than men to receive depression treatment [AOR=1.53; 95\% CI=(1.13,2.08)] among the individuals with cancer and depression. Racial/ethnicity groups other than whites were also found to less likely to receive any depression treatment. As compared to whites, the AOR for African Americans were 0.38 [95\% $\mathrm{CI}=(0.25,0.58)]$ and the AOR for Latinos were $0.41[95 \% \mathrm{CI}=(0.29,0.58)]$. Also among adults with cancer and depression, adults aged 65 years and above were $73 \%$ more likely than those who were in the $22-39$ years to receive any depression treatment with $\mathrm{AOR}=1.73$ and $95 \%$ $\mathrm{CI}=(1.03,2.92)$. And as compared to individuals who had lower number of physician visits, individuals in the groups quintile 5 and 4 had higher odds of receiving any depression treatment [the AOR for quintile 5 as compared to quintile 1 was 4.15 with $95 \% \mathrm{CI}=(2.64,6.53)$ and for quintile 4 was 3 with $95 \% \mathrm{CI}=(1.98,1.71)$ ].

Table 2. Weighted Percent of receipt of any depression treatment for individuals with Depression and Cancer or Cardio-metabolic condition. Medical Expenditure Panel Survey, 2006-2008.

\begin{tabular}{|c|c|c|c|c|}
\hline Characteristics & $\begin{array}{l}\text { Cancer } \\
\text { Wt } \%\end{array}$ & $\begin{array}{c}\text { Cardio-metabolic } \\
\text { Wt } \%\end{array}$ & P-value & Sig \\
\hline All & 78 & 81.7 & 0.139 & \\
\hline $\begin{array}{l}\text { Gender } \\
\text { Women } \\
\text { Men }\end{array}$ & $\begin{array}{l}78.2 \\
77.7\end{array}$ & $\begin{array}{l}83.3 \\
78.4\end{array}$ & $\begin{array}{l}0.045 \\
0.836\end{array}$ & * \\
\hline $\begin{array}{l}\text { Race/ethnicity } \\
\text { White } \\
\text { African American } \\
\text { Latino } \\
\text { Other }\end{array}$ & $\begin{array}{l}81.8 \\
53.8 \\
73.3 \\
36.8\end{array}$ & $\begin{array}{c}85 \\
70.6 \\
69 \\
71.7\end{array}$ & $\begin{array}{c}0.192 \\
0.003 \\
0.539 \\
0.00\end{array}$ & $\begin{array}{l}* * \\
* * *\end{array}$ \\
\hline $\begin{array}{l}\text { Age in years } \\
22-39 \\
40-49 \\
50-64 \\
65 \text { years and above }\end{array}$ & $\begin{array}{l}54.2 \\
72.5 \\
80.5 \\
82.4\end{array}$ & $\begin{array}{c}75.8 \\
74.3 \\
84 \\
84.5\end{array}$ & $\begin{array}{l}0.00 \\
0.626 \\
0.267 \\
0.444\end{array}$ & $* * *$ \\
\hline $\begin{array}{l}\text { Poverty status } \\
\text { Poor } \\
\text { Near poor } \\
\text { Middle income } \\
\text { High income }\end{array}$ & $\begin{array}{c}78 \\
77.9 \\
78.9 \\
77.5\end{array}$ & $\begin{array}{l}75.7 \\
84.3 \\
80.8 \\
83.9\end{array}$ & $\begin{array}{l}0.463 \\
0.014 \\
0.572 \\
0.068\end{array}$ & * \\
\hline $\begin{array}{l}\text { Health insurance } \\
\text { Private } \\
\text { Public } \\
\text { Uninsured }\end{array}$ & $\begin{array}{c}78 \\
80.8 \\
59.8\end{array}$ & $\begin{array}{l}83.6 \\
82.9 \\
61.3\end{array}$ & $\begin{array}{l}0.046 \\
0.435 \\
0.738\end{array}$ & * \\
\hline $\begin{array}{l}\text { Perceived general health } \\
\text { Excellent/very good } \\
\text { Good } \\
\text { Fair/poor }\end{array}$ & $\begin{array}{l}75.3 \\
73.9 \\
81.5\end{array}$ & $\begin{array}{l}80.8 \\
81.3 \\
82.4\end{array}$ & $\begin{array}{l}0.024 \\
0.027 \\
0.767\end{array}$ & $\begin{array}{l}* \\
*\end{array}$ \\
\hline $\begin{array}{l}\text { Perceived mental health } \\
\text { Excellent/very good } \\
\text { Good } \\
\text { Fair/poor }\end{array}$ & $\begin{array}{c}76 \\
78.3 \\
79.8\end{array}$ & $\begin{array}{c}80.2 \\
82 \\
82.8\end{array}$ & $\begin{array}{l}0.219 \\
0.227 \\
0.423\end{array}$ & \\
\hline $\begin{array}{l}\text { Current smoking } \\
\text { Current smoker } \\
\text { Other }\end{array}$ & $\begin{array}{c}77 \\
80.2\end{array}$ & $\begin{array}{l}76.7 \\
83.7\end{array}$ & $\begin{array}{l}0.936 \\
0.104\end{array}$ & \\
\hline $\begin{array}{l}\text { Physical activity } \\
3 \text { times/week } \\
\text { No exercise }\end{array}$ & $\begin{array}{l}76.2 \\
80.6\end{array}$ & $\begin{array}{c}79 \\
83.1\end{array}$ & $\begin{array}{l}0.424 \\
0.328\end{array}$ & \\
\hline $\begin{array}{l}\text { Body mass index } \\
\text { Underweight/normal } \\
\text { Overweight } \\
\text { Obese }\end{array}$ & $\begin{array}{l}78.6 \\
77.7 \\
80.6\end{array}$ & $\begin{array}{c}78.9 \\
80 \\
83.1\end{array}$ & $\begin{array}{l}0.906 \\
0.455 \\
0.367\end{array}$ & \\
\hline $\begin{array}{l}\text { Number of visits to the physician } \\
\text { Quintile } 5 \\
\text { Quintile } 4 \\
\text { Quintile } 3 \\
\text { Quintile 2 } \\
\text { Quintile 1 }\end{array}$ & $\begin{array}{l}90.5 \\
83.5 \\
81.9 \\
66.6 \\
52.2\end{array}$ & $\begin{array}{c}91.3 \\
90 \\
80.3 \\
77.9 \\
70\end{array}$ & $\begin{array}{l}0.00 \\
0.00 \\
0.634 \\
0.022 \\
0.758\end{array}$ & $\begin{array}{c}* * * \\
* * * \\
*\end{array}$ \\
\hline
\end{tabular}

Based on 2171 living adults over age 21 who were alive during the calendar years, aged 21 years older, with self-reported depression and cancer or cardio-metabolic condition from MEPS data in years 2006,2007 and 2008. Asterisks represent significant group differences by receipt of any depression treatment in each of the two condition groups using chi-square tests. Sig, Significance. ${ }^{* * *} \mathrm{P}<0.001 ;{ }^{* *} 0.001 \leq \mathrm{P}<0.01 ;{ }^{*} 0.01 \leq \mathrm{P}<0.05$ 
Table 3. Adjusted odds ratios and $95 \%$ confidence interval from logistic regressions on receipt of any depression treatment among individuals with depression and cancer or cardio-metabolic condition. Medical Expenditure Panel Survey, 2006-2008.

\begin{tabular}{|c|c|c|c|c|}
\hline & AOR & $95 \%$ CI & P-value & Sig \\
\hline $\begin{array}{l}\text { Condition } \\
\text { Cancer } \\
\text { Cardio-metabolic }\end{array}$ & $\begin{array}{l}0.67 \\
\text { Ref }\end{array}$ & {$[0.49,0.92]$} & 0.0132 & $*$ \\
\hline $\begin{array}{l}\text { Gender } \\
\text { Women } \\
\text { Men } \\
\end{array}$ & $\begin{array}{l}1.53 \\
\text { Ref }\end{array}$ & {$[1.13,2.08]$} & 0.0065 & ** \\
\hline $\begin{array}{l}\text { Race/ethnicity } \\
\text { African American } \\
\text { Latino } \\
\text { Other } \\
\text { White }\end{array}$ & $\begin{array}{l}0.38 \\
0.41 \\
0.34 \\
\text { Ref }\end{array}$ & $\begin{array}{l}{[0.25,0.58]} \\
{[0.29,0.58]} \\
{[0.20,0.57]}\end{array}$ & $\begin{array}{l}<0.0001 \\
<0.0001 \\
<0.0001\end{array}$ & $\begin{array}{l}* * * \\
* * * \\
* * *\end{array}$ \\
\hline $\begin{array}{l}\text { Age } \\
65 \text { years and above } \\
50-64 \text { years } \\
40-49 \text { years } \\
22-39 \text { years }\end{array}$ & $\begin{array}{l}1.73 \\
1.74 \\
1.08 \\
\text { Ref }\end{array}$ & $\begin{array}{l}{[1.03,2.92]} \\
{[1.08,2.82]} \\
{[0.67,1.74]}\end{array}$ & $\begin{array}{l}0.0387 \\
0.0233 \\
0.7495\end{array}$ & * \\
\hline $\begin{array}{l}\text { Marital status } \\
\text { Widow } \\
\text { Separated or divorced } \\
\text { Never married } \\
\text { Married }\end{array}$ & $\begin{array}{l}0.44 \\
0.65 \\
0.73 \\
\text { Ref }\end{array}$ & $\begin{array}{l}{[0.28,0.67]} \\
{[0.46,0.93]} \\
{[0.45,1.19]}\end{array}$ & $\begin{array}{l}0.0002 \\
0.0175 \\
0.2048\end{array}$ & $\begin{array}{c}* * * \\
*\end{array}$ \\
\hline $\begin{array}{l}\text { Metropolitan status } \\
\text { Non-metro } \\
\text { Metro }\end{array}$ & $\begin{array}{l}1.16 \\
\text { Ref }\end{array}$ & {$[0.81,1.67]$} & 0.4236 & \\
\hline $\begin{array}{l}\text { Education } \\
\text { Less than High school } \\
\text { High school } \\
\text { Above High school }\end{array}$ & $\begin{array}{l}0.97 \\
0.97 \\
\text { Ref }\end{array}$ & $\begin{array}{l}{[0.67,1.40]} \\
{[0.70,1.34]}\end{array}$ & $\begin{array}{l}0.8624 \\
0.8697\end{array}$ & \\
\hline $\begin{array}{l}\text { Employment status } \\
\text { Not employed } \\
\text { Employed } \\
\end{array}$ & $\begin{array}{l}1.08 \\
\text { Ref }\end{array}$ & {$[0.76,1.54]$} & 0.6762 & \\
\hline $\begin{array}{l}\text { Poverty status } \\
\text { Poor } \\
\text { Near poor } \\
\text { Middle income } \\
\text { High income }\end{array}$ & $\begin{array}{l}1.01 \\
1.42 \\
0.99 \\
\text { Ref }\end{array}$ & $\begin{array}{l}{[0.61,1.69]} \\
{[0.95,2.12]} \\
{[0.70,1.41]}\end{array}$ & $\begin{array}{l}0.9612 \\
0.0904 \\
0.9589\end{array}$ & \\
\hline $\begin{array}{l}\text { Health insurance } \\
\text { Public insurance } \\
\text { Uninsured } \\
\text { Private insurance } \\
\end{array}$ & $\begin{array}{l}1.19 \\
0.55 \\
\text { Ref }\end{array}$ & $\begin{array}{l}{[0.83,1.71]} \\
{[0.37,0.81]}\end{array}$ & $\begin{array}{l}0.346 \\
0.003\end{array}$ & $* *$ \\
\hline $\begin{array}{l}\text { Perceived general health } \\
\text { Fair/poor } \\
\text { Good } \\
\text { Excellent Nery good }\end{array}$ & $\begin{array}{l}0.75 \\
0.79 \\
\text { Ref }\end{array}$ & $\begin{array}{l}{[0.51,1.09]} \\
{[0.52,1.20]}\end{array}$ & $\begin{array}{c}0.275 \\
0.1352\end{array}$ & \\
\hline $\begin{array}{l}\text { Perceived mental health } \\
\text { Fair/poor } \\
\text { Good } \\
\text { Excellent/very good }\end{array}$ & $\begin{array}{l}1.41 \\
1.23 \\
\text { Ref }\end{array}$ & $\begin{array}{l}{[0.98,2.02]} \\
{[0.90,1.67]}\end{array}$ & $\begin{array}{l}0.1951 \\
0.0636\end{array}$ & \\
\hline $\begin{array}{l}\text { Current smoking status } \\
\text { Current smoker } \\
\text { Other }\end{array}$ & $\begin{array}{l}0.83 \\
\text { Ref }\end{array}$ & {$[0.62,1.11]$} & 0.2118 & \\
\hline $\begin{array}{l}\text { Physical activity } \\
\text { No exercise/week } \\
\text { Exercise } 3 \text { times/week }\end{array}$ & $\begin{array}{l}1.25 \\
\text { Ref }\end{array}$ & {$[0.96,1.63]$} & 0.1032 & \\
\hline $\begin{array}{l}\text { Body mass index } \\
\text { Over-weight } \\
\text { Obese } \\
\text { Underweight/normal weight }\end{array}$ & $\begin{array}{c}1 \\
1.25 \\
\operatorname{Ref}\end{array}$ & $\begin{array}{l}{[0.69,1.44]} \\
{[0.92,1.71]}\end{array}$ & $\begin{array}{l}0.9973 \\
0.1539\end{array}$ & \\
\hline $\begin{array}{l}\text { Number of visits to the physician } \\
\text { Quintile } 5 \\
\text { Quintile } 4 \\
\text { Quintile } 3 \\
\text { Quintile 2 } \\
\text { Quintile } 1\end{array}$ & $\begin{array}{l}4.15 \\
3 \\
1.62 \\
1.33 \\
\text { Ref }\end{array}$ & $\begin{array}{l}{[2.64,6.53]} \\
{[1.98,4.55]} \\
{[1.11,2.36]} \\
{[0.97,1.82]}\end{array}$ & $\begin{array}{l}<0.0001 \\
<0.0001 \\
0.013 \\
0.0763\end{array}$ & $\begin{array}{c}* * * \\
* * * \\
* \\
*\end{array}$ \\
\hline
\end{tabular}

Based on 2171 living adults over age 21 who were alive during the calendar years with self-reported depression and cancer or cardio-metabolic condition from MEPS data in years 2006, 2007 and 2008. Asterisks represent significant relationship between any depression treatment and the subgroup compared to the reference group based on multiple variable logistic regressions. The reference groups in the regression model were the cardio-metabolic condition, men, white race/ethnicity, age group 22-39years, married, metro region, above high school education, employed group, high income group, privately insured, excellent/very good general health, excellent/very good mental, underweight/normal group, and number of physician visits-quintile. The regressions also include intercept terms. AOR, Adjusted Odds Ratio; Ref, Reference group; Sig, general health, excellent/very good mental, underweight
Significance; ${ }^{* * *} \mathrm{P}<0.001 ;{ }^{* *} 0.001<\mathrm{P}<0.01 ;{ }^{*} 0.01<\mathrm{P}<0.05$. 


\section{Discussion}

The current study was set out to examine the association between any depression treatment (antidepressants and/or psychotherapy) and presence of cancer diagnosis, using a comparative group of individuals with cardio-metabolic conditions; who may be similar in terms of depression prevalence, the negative association between depression and health outcomes and competing demands of clinical care. We found that among adults with depression, those with cancer were less likely to receive any treatment for depression compared to those cardio-metabolic conditions. As we mentioned before, this relationship was initially not statistically significant in a multivariate regression model which controlled for socio-demographic, access to care, health status, and lifestyle risk factors related variables. However this relationship became statistically significant when number of physician visits (which could serve as an important indicator of the individual's contact with the healthcare system) was added to the model, suggesting that it may be an important predictor of the relationship between any depression treatment received and presence of cancer. These findings need to be placed in the context of increased recognition of depression management among individuals with cancer as a critical component of cancer care and the development of the subspecialty discipline psychooncology to provide holistic cancer and mental health treatment for individuals with cancer. $17,18,38$

An examination of the association between any depression treatment and demographic characteristics, socio-economic status, access to care, health status, and lifestyle risk factors among individuals with cancer revealed some interesting findings. The racia/ethnic disparities in depression care found in our study also mirror those found in the general population, where an overwhelming majority of studies on racial disparities in diagnosis and depression treatment rates revealed that African Americans and Latinos were less likely to receive depression treatment. ${ }^{39}$ As in the general population, among individuals with cancer and depression racial minorities compared to whites were less likely to receive any depression treatment even after controlling for access to care, socioeconomic, health status and lifestyle risk factors. These findings suggest that racial/ethnic disparities persist despite the continued efforts to eliminate the same.

We also found that overall individuals with cancer had greater outpatient visits as compared to those with cardio-metabolic conditions. However, individuals with cancer and depression were less likely to receive any treatment for depression despite such increased contact with healthcare system as compared to those with cardio-metabolic conditions and depression. Evidence from prior research suggests that depression treatment may be neglected due to competing demands of other conditions such as cancer.5,40 Also, cancer has often been considered a clinically dominant condition consuming the attention of the medical care providers and eclipsing the management of other co-occurring conditions including depression. ${ }^{28,29}$ Taken together our findings and prior literature, it can be speculated that the presence of cancer may crowd out of attention to depression management.

We also found that among individuals with cancer, approximately one-quarter (22\%) did not receive any depression treatment, which is consistent with published literature in cancer. ${ }^{20}$ Depression has been reported to be undertreated in individuals with cancer.41,42 Some physicians may consider cancer as a priority condition or perceive depression as a natural reaction to the diagnosis of cancer. They may even be skeptical about their expertise in treating depression in individuals with cancer. ${ }^{30}$ Indeed, some physicians have reported the presence of cancer as one of the reasons for overruling guidelines for depression treatment. ${ }^{43} \mathrm{~A}$ survey of healthcare professionals from Canada indicated that $29 \%$ of primary care providers and $23 \%$ oncologists indicated that they may not adopt clinical guidelines in their practices. ${ }^{17}$ In another survey of European and American oncologists conducted as a quality improvement program, $41 \%$ agreed that most oncologists they know are not experts in managing psychological symptoms in advanced care; and between 17$22 \%$ oncologists said that they had never worked in collaboration with any psychologists or psychiatrists. ${ }^{4}$

Despite increased awareness of depression, lack of robust evidence on the effectiveness of depression treatment among individuals with cancer may discourage healthcare providers in initiating depression treatment. A systematic review of few randomized controlled trials of antidepressant and psychotherapy among individuals with cancer concluded that the efficacy and tolerability of antidepressants and psychotherapeutic interventions are questionable. ${ }^{27}$ Also, none of the randomized clinical trials support the effectiveness of psychotherapy for diagnosed depression among individuals with cancer. 45 Future research is needed to document the effectiveness of depression treatment in terms of both the cancer and noncancer related outcomes in the real-world practice setting.

Strengths and limitations of the current study have to be taken into account while interpreting the findings from the study. The strengths include use of nationally representative data, availability of a comprehensive list of variables that may affect depression treatment, and availability of an appropriate com- parison group. There were some limitations to our study. All data for the study is derived from self-reports and thus are subject to recall bias. However, upon collecting the information from the household survey respondents, MEPS contacts a sample of medical providers by telephone to obtain and/or confirm the information which the respondents cannot accurately provide. And information on the MEPS household reported medical condition data has been compared with provider reported data, and it has been found to be reliable in published literature. 46 We could only identify associations, and causality could not be determined here due to the cross-sectional and retrospective nature of our study design. Presence of depression in our study population was based on selfreport only and no diagnostic instrument was used by MEPS to validate the depression diagnosis. We could not assess the severity and the duration of the diseases, which may have shed light on the role of the clinical characteristics on use of depression treatment. We also did not analyze treatment rates stratified by the cancer site due to the limited sample size. Although we had sufficient number of individuals with depression, we could not separately analyze psychotherapy and antidepressant due to small sample sizes with psychotherapy use (Appendix). We only measured general psychotherapy and could not distinguish between types of psychotherapies. We also could not determine patient preferences in terms of choosing between psychotherapy and prescription antidepressants, which may be important in determining appropriate care. Lastly, our analysis was restricted to only patient-level factors, and we did not consider characteristics of the health-care provider; which may influence depression treatment among individuals with cancer.

Our study extends the prior literature and provides information on nation-wide depression treatment practices in real-world settings in the US, in spite of the limitations. By documenting a lower-likelihood of depression treatment among individuals with cancer despite increased contact with the healthcare system, our study highlights the possibility that competing demands may crowd out treatment for depression. The association between depression treatment and presence or diagnosis of cancer remains poorly understood and further research is needed to probe the reasons for nontreatment of depression. Designing and implementing appropriate interventions to impart knowledge and skills related to screening, assessment and management of depression among individuals with cancer is essential. And recognition of importance of depression treatment by cancer healthcare professionals or better integration of depression treatment in routine cancer care is recommended. 


\section{References}

1. Goldberg D. The detection and treatment of depression in the physically ill. World Psychiatry 2010;9:16-20.

2. Pouwer F, Beekman AT, Nijpels G, et al. Rates and risks for co-morbid depression in patients with type 2 diabetes mellitus: results from a community-based study. Diabetologia 2003;46:892-8.

3. van't Spijker A, Trijsburg RW, Duivenvoorden HJ. Psychological sequelae of cancer diagnosis: a meta-analytical review of 58 studies after 1980. Psychosom Med 1997; 59:280-93.

4. Leon FG, Ashton AK, D'Mello DA, et al. Depression and comorbid medical illness: therapeutic and diagnostic challenges. J Fam Pract 2003:S19-33.

5. Nutting PA, Rost K, Smith J, et al. Competing demands from physical problems: effect on initiating and completing depression care over 6 months. Arch Fam Med 2000;9:1059-64.

6. Harman JS, Edlund MJ, Fortney JC. Disparities in the adequacy of depression treatment in the United States. Psychiatr Serv 2004;55:1379-85.

7. Ashbury FD, Madlensky L, Raich P, et al. Antidepressant prescribing in community cancer care. Support Care Cancer 2003;11: 278-85.

8. Fisch M. Treatment of depression in cancer. J Natl Cancer Inst Monogr 2004;105-11.

9. Lichtman JH, Bigger JT Jr, Blumenthal JA, et al. Depression and coronary heart disease: recommendations for screening, referral, and treatment: a science advisory from the American Heart Association Prevention Committee of the Council on Cardiovascular Nursing, Council on Clinical Cardiology, Council on Epidemiology and Prevention, and Interdisciplinary Council on Quality of Care and Outcomes Research: endorsed by the American Psychiatric Association. Circulation 2008;118:1768-75.

10. Carney RM, Blumenthal JA, Freedland KE, et al. Depression and late mortality after myocardial infarction in the enhancing recovery in coronary heart disease (ENRICHD) study. Psychosom Med 2004; 66:466-74.

11. Lustman PJ, Griffith LS, Clouse RE, et al. Effects of nortriptyline on depression and glycemic control in diabetes: results of a double-blind, placebo-controlled trial. Psychosom Med 1997;59:241-50.

12. Ross L, Petersen MA, Johnsen AT, et al. Are different groups of cancer patients offered rehabilitation to the same extent? A report from the population-based study The Cancer Patient's World. Support Care
Cancer 2012;20:1089-100.

13. Khan NF, Ward AM, Watson E, Rose PW. Consulting and prescribing behaviour for anxiety and depression in long-term survivors of cancer in the UK. Eur J Cancer 2010;46:3339-44.

14. Massie MJ, Lloyd-Williams M, Irving G, and Miller K. The prevalence of depression in people with cancer. In: Kissane DW, Maj M, and Sartorius N, editor. Depression and Cancer. Oxford: Willey-Blackwell; 2011. pp $1-36$.

15. Okamura H, Watanabe T, Narabayashi M, et al. Psychological distress following first recurrence of disease in patients with breast cancer: prevalence and risk factors. Breast Cancer Res Treat 2000;61:131-7.

16. Irving G, Lloyd-Williams M. Depression in advanced cancer. Eur J Oncol Nurs 2010; 14:395-9.

17. Rodin G, Lloyd N, Katz M, et al. The treatment of depression in cancer patients: a systematic review. Support Care Cancer 2007;15:123-36.

18. Rayner L, Price A, Hotopf M, Higginson IJ. The development of evidence-based European guidelines on the management of depression in palliative cancer care. Eur J Cancer 2011;47:702-12.

19. Twillman RK, Manetto C. Concurrent psychotherapy and pharmacotherapy in the treatment of depression and anxiety in cancer patients. Psychooncology 1998;7: 285-90.

20. Gill JM, Klinkman MS, Chen YX. Antidepressant medication use for primary care patients with and without medical comorbidities: a national electronic health record (EHR) network study. J Am Board Fam Med 2010;23:499-508.

21. Ell K, Sanchez K, Vourlekis B, Lee PJ, et al. Depression, correlates of depression, and receipt of depression care among lowincome women with breast or gynecologic cancer. J Clin Oncol 2005;23:3052-60.

22. Nolen-Hoeksema S. Gender differences in depression. Curr Dir Psychol Sci 2001; 10: 5173-6.

23. Massie MJ. Prevalence of depression in patients with cancer. J Natl Cancer Inst Monogr 2004;57-71.

24. Musselman DL, Betan E, Larsen H, Phillips LS. Relationship of depression to diabetes types 1 and 2: epidemiology, biology, and treatment. Biol Psychiatry 2003;54:317-29.

25. Rutledge TP, Reis VA, Linke SE, et al. Depression in heart failure: a meta-analytic review of prevalence, intervention effects, and associations with clinical outcomes. J Am Coll Cardiol 2006;48:1527-37.

26. Katon W, Ciechanowski P. Impact of major depression on chronic medical illness. J Psychosom Res 2002;53:859-63.

27. Williams S, Dale J. The effectiveness of treatment for depression/depressive symptoms in adults with cancer: a systematic review. Br J Cancer 2006;94:372-90.

28. Ogle KS, Swanson GM, Woods N, Azzouz F. Cancer and comorbidity: redefining chronic diseases. Cancer 2000;88:653-63.

29. Piette JD, Kerr EA. The impact of comorbid chronic conditions on diabetes care. Diabetes Care 2006;29:725-31.

30. Passik SD, Dugan W, McDonald MV, et al. Oncologists' recognition of depression in their patients with cancer. J Clin Oncol 1998;16:1594-600.

31. Kadan-Lottick NS, Vanderwerker LC, Block $\mathrm{SD}$, et al. Psychiatric disorders and mental health service use in patients with advanced cancer: a report from the coping with cancer study. Cancer 2005;104:287281.

32. AHRQ. MEPS HC-120: 2008 Medical Conditions. Center for Financing, Access, and Cost Trends 540 Gaither Road Rockville, MD 20850: Agency for Healthcare Research and Quality. Available from http://www.meps.ahrq.gov/mepsweb/data stats/download_data/pufs/h120/h120doc.p df. Accessed: August 2012.

33. Meduru P, Helmer D, Rajan M, Tseng CL, Pogach L, Sambamoorthi U. Chronic illness with complexity: implications for performance measurement of optimal glycemic control. J Gen Intern Med 2007 Dec;22 Suppl 3:408-418.

34. Pampallona S, Bollini P, Tibaldi G, Kupelnick B, Munizza C. Combined pharmacotherapy and psychological treatment for depression: a systematic review. Arch Gen Psychiatry 2004 Jul;61(7):714-719.

35. Stagnitti, M. N. Trends in the Use and Expenditures for the Therapeutic Class Prescribed Psychotherapeutic Agents and All Subclasses, 1997 and 2004. Statistical Brief \#163. February 2007. Agency for Healthcare Research and Quality, Rockville, MD. http://www.meps.ahrq.gov/ mepsweb/data_files/publications/st163/sta t163.pdf.

36. AHRQ. MEPS H-118g: 2008 Office based Medical Provider Visits. Center for Financing, Access, and Cost Trends 540 Gaither Road Rockville, MD 20850: Agency for Healthcare Research and Quality; 2010 [cited 2012 August 29]; Available from http://www.meps.ahrq.gov/mepsweb/data stats/download_data/pufs/h118g/h118gdoc .pdf

37. Tseng CL, Sambamoorthi U, Rajan M, et al. Are there gender differences in diabetes care among elderly Medicare enrolled veterans? J Gen Intern Med 2006;21:S47-53.

38. Holland JC. History of psycho-oncology: overcoming attitudinal and conceptual barriers. Psychosom Med 2002;64:206-21.

39. Simpson SM, Krishnan LL, Kunik ME, Ruiz 
P. Racial disparities in diagnosis and treatment of depression: a literature review. Psychiatr Q 2007;78:3-14.

40. Rost K, Nutting P, Smith J, et al. The role of competing demands in the treatment provided primary care patients with major depression. Arch Fam Med 2000;9:150-4.

41. Fallowfield L, Ratcliffe D, Jenkins V, Saul J. Psychiatric morbidity and its recognition by doctors in patients with cancer. Br J Cancer 2001;84:1011-5.

42. Suppli NP, Deltour I, Damkjaer LH, et al.
Factors associated with the prescription of antidepressive medication to breast cancer patients. Acta Oncol 2011;50:243-51.

43. Greenberg DB. Barriers to the treatment of depression in cancer patients. J Natl Cancer Inst Monogr 2004;127-35.

44. Cherny NI, Catane R, European Society of Medical Oncology Taskforce on Palliative and Supportive Care. Attitudes of medical oncologists toward palliative care for patients with advanced and incurable cancer: report on a survery by the European
Society of Medical Oncology Taskforce on Palliative and Supportive Care. Cancer 2003;98:2502-10.

45. Akechi T, Okuyama T, Onishi J, et al. Psychotherapy for depression among incurable cancer patients. Cochrane Database Syst Rev 2008:CD005537.

46. Machlin S, Cohen J, Elixhauser A, et al. Sensitivity of household reported medical conditions in the medical expenditure panel survey. Med Care 2009;47:618-25. 